\title{
Numerical-Experimental Determination of Stress and Deformation State in Connecting Lugs with the Effect of Contact Area Size
}

\author{
Đorđe ĐURĐEVIĆ, Nina ANĐELIĆ, Taško MANESKI, Vesna MILOŠEVIĆ-MITIĆ, Andrijana ĐURĐEVIĆ, Pejo KONJATIĆ
}

\begin{abstract}
The present paper describes numerical and experimental methodology for the analysis of stress and deformation state in structural elements with geometrical discontinuities. The research is based on structural elements of the connecting lug type. The stress and deformation state was determined as the contact area size between the axle and the connecting lug was changing. Numerical analysis was conducted by applying the finite element method in a "KOMIPS" software package. Experiments were performed at the Laboratory for stress and deformation measurements, Faculty of Mechanical Engineering, University of Belgrade, using "GOM" equipment and "ARAMIS" software application (DIC). This paper demonstrates how it is possible to anticipate the results by applying FEM. A short review of current research in the field of structural elements with geometrical discontinuities is given within the framework of the paper.
\end{abstract}

Keywords: connecting lug; DIC; FEM; stress concentration; strain measurement

\section{INTRODUCTION}

This section presents a review of hitherto conducted research and results achieved in the area of stress and deformation state of structural elements with geometrical discontinuities. It is necessary to reliably determine exploitation behaviour of structural elements by applying contemporary numerical-experimental methods. The objective of the paper is to investigate stress and deformation field at the points of geometrical discontinuities of structural elements under the action of axial loading. Theoretical and experimental investigations show that in the zones, where the loaded element contour changes abruptly the local increase of stress occurs. Such zones are notches, holes of different shapes, points of abrupt curvature, as well as contact points between two elements mutually acting upon each other. Peterson earlier reported the results from this field [1]. The most common examples causing stress concentration are given in [1-4]. The investigation was carried out using the connecting lug type models loaded by axial forces. Theoretical solutions for the plates connected by threaded fasteners were provided by $\mathrm{Yu}$ and Rowlands in [5]. Similar problems with stress concentrations are discussed in [6,7]. Experimental results (Aramis) and the results obtained by numerical methods from above mentioned fields were reported in $[8,9]$. All designed and constructed structures inevitably have a change in geometry that causes stress concentration. Standard methods of calculations and testing cannot accurately determine and anticipate the intensity of geometrical discontinuity effect on the structure deformation and stress.

\section{ANALYSIS OF CONNECTING LUGS}

Geometric shape of analyzed connecting lugs' structural elements made of structural steel S355J2 (tensile strength $R_{\mathrm{M}}=490 \div 630 \mathrm{MPa}$ and yield strength $R_{\mathrm{P} 0.2}=355$ $\mathrm{MPa}$ ) is presented in Fig. 1. The analysis included three connecting lugs with dimensions as shown in Tab. 1.

Axial distances between holes of analyzed connecting lugs U1, U2 and U3 are respectively $86 \mathrm{~mm} ; 109,5 \mathrm{~mm}$ and $200 \mathrm{~mm}$. Tab. 2 shows adopted axial loadings.

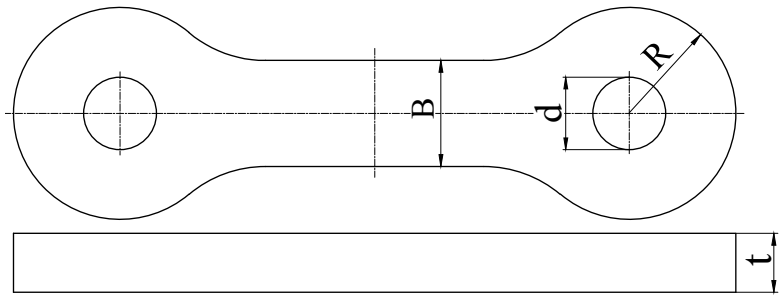

Figure 1 Geometric shape of analyzed connecting lug

Table 1 Dimensions of connecting lugs according to Fig. 1

\begin{tabular}{|c|c|c|c|c|c|}
\hline $\begin{array}{c}\text { Designation of } \\
\text { con. lug }\end{array}$ & $d / \mathrm{mm}$ & $R / \mathrm{mm}$ & $B / \mathrm{mm}$ & $t / \mathrm{mm}$ & $\frac{2 R}{d}$ \\
\hline $\mathrm{U} 1$ & 12 & 18 & 18 & 10 & 3 \\
\hline $\mathrm{U} 2$ & 14 & 22,5 & 22 & 10 & 3,21 \\
\hline $\mathrm{U} 3$ & 30 & 35 & 30 & 10 & 2,33 \\
\hline
\end{tabular}

Table 2 Loading of connecting lugs

\begin{tabular}{|c|c|}
\hline Designation of con. lug & Force $F / \mathrm{kN}$ \\
\hline $\mathrm{U} 1$ & 20 \\
\hline $\mathrm{U} 2$ & 20 \\
\hline $\mathrm{U} 3$ & 30 \\
\hline
\end{tabular}

\section{FINITE ELEMENT ANALYSIS}

\subsection{General}

FEM analysis is one of the most widely used engineering analysis techniques to solve different engineering problems. In this paper, numerical analysis was conducted by the application of finite elements using "KOMIPS" software [10].

\subsection{Geometric Modelling, Finite Element Mesh and Numerical Analysis}

The model was built in such a way as to consist of elements of the plate type and elements of the contact type. The contact between the axle and the connecting lug was modelled via contact elements. The clearance size between the connecting lug and the axle directly affects the contact area size. The total angle contacts adopted were as follows: $36^{\circ}, 54^{\circ}, 90^{\circ}, 126^{\circ}, 162^{\circ}, 180^{\circ}$. The axle was considered as a rigid element and was used for loading input. Fig. 2 presents finite element meshes of the appropriate connected lugs. 
U1

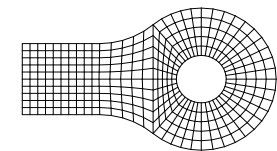

$\mathrm{U} 2$

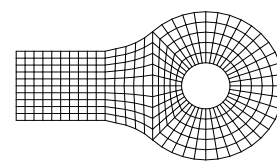

U3

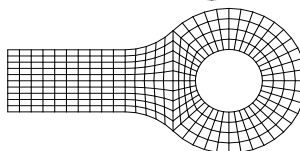

Figure 2 Finite element meshes of connecting lugs

Fig. 3 shows deformation of a connecting lug U1, depending on contact angle.

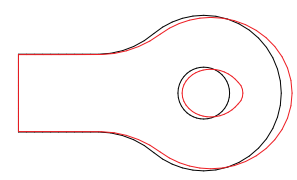

$\mathrm{U} 1-36^{\circ}$

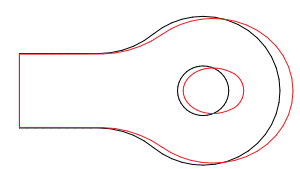

$\mathrm{U} 1-90^{\circ}$

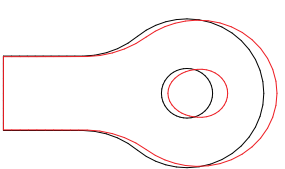

$\mathrm{U} 1-36^{\circ}$

Figure 3 Deformation of the U1 model

Calculated values of maximum deformation of discussed connecting lugs' types U1, U2 and U3 are presented in Tab. 3 .

Table 3 Maximum deformation of connecting lugs

\begin{tabular}{|c|c|c|}
\hline Designation of con. lug & Contact angle $^{/}$ & Deformation $/ \mathrm{mm}$ \\
\hline \multirow{4}{*}{ U1 } & 36 & 0,067 \\
\cline { 2 - 3 } & 54 & 0,0588 \\
\cline { 2 - 3 } & 90 & 0,0501 \\
\cline { 2 - 3 } & 126 & 0,0459 \\
\cline { 2 - 3 } & 162 & 0,0444 \\
\hline \multirow{4}{*}{ U2 } & 180 & 0,0443 \\
\cline { 2 - 3 } & 36 & 0,067 \\
\cline { 2 - 3 } & 54 & 0,0589 \\
\cline { 2 - 3 } & 90 & 0,0505 \\
\cline { 2 - 3 } & 126 & 0,0467 \\
\cline { 2 - 3 } & 162 & 0,0453 \\
\hline \multirow{4}{*}{ U3 } & 180 & 0,0452 \\
\cline { 2 - 3 } & 36 & 0,168 \\
\cline { 2 - 3 } & 54 & 0,145 \\
\cline { 2 - 3 } & 90 & 0,121 \\
\cline { 2 - 3 } & 126 & 0,110 \\
\cline { 2 - 3 } & 162 & 0,105 \\
\cline { 2 - 3 } & 180 & 0,105 \\
\hline
\end{tabular}

Figs. 4, 5, 6 show von Mises stress field $(\sigma)$ for connecting lugs, depending on the total contact angle.

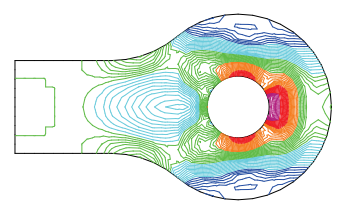

$\mathrm{U} 1-36^{\circ}$

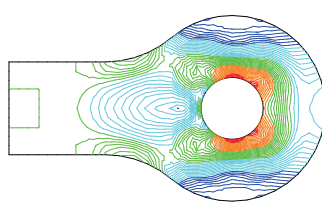

$\mathrm{U} 1-90^{\circ}$

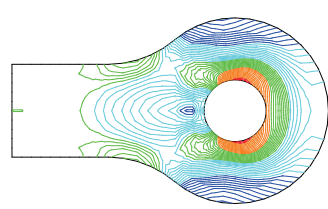

$\mathrm{U} 1-162^{\circ}$

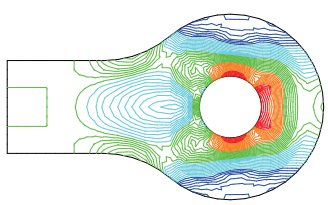

$\mathrm{U} 1-54^{\circ}$

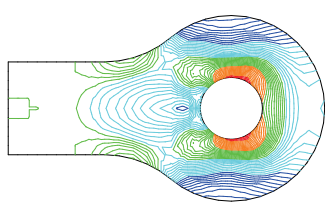

$\mathrm{U} 1-126^{\circ}$

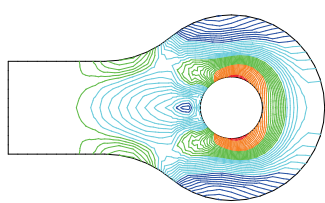

$\mathrm{U} 1-180^{\circ}$

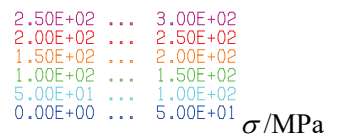

Figure 4 Representation of von Mises stress field $(\sigma)$ with associated scale for connecting lug U1

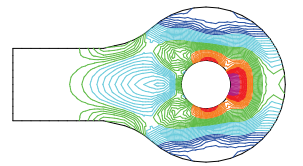

$\mathrm{U} 2-36^{\circ}$

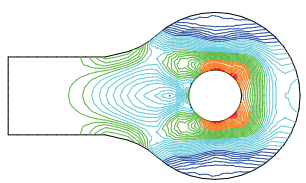

$\mathrm{U} 2-90^{\circ}$

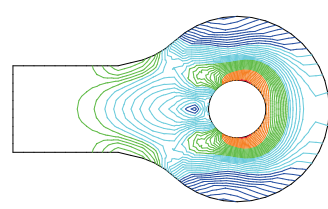

$\mathrm{U} 2-162^{\circ}$

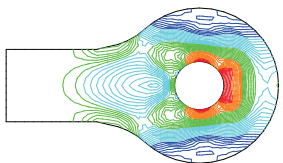

$\mathrm{U} 2-54^{\circ}$

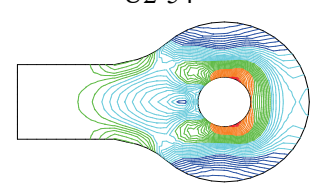

$\mathrm{U} 2-126^{\circ}$

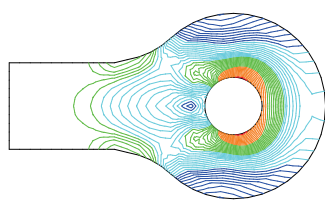

$\mathrm{U} 2-180^{\circ}$

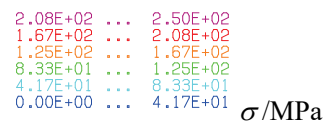

Figure 5 Representation of von Mises stress field $(\sigma)$ with associated scale for connecting lug U2

Figs. 7 and 8 display diagrams of deformation and maximum von Mises stress dependence on contact angle size between the axle and the connecting lug. The results are presented for connecting lugs U1, U2 and U3. The cause of unfavourable behaviour of the connecting lug U3 is small ratio between $2 R$ and $d$, as presented in Tab. 1. Gradient of lines in diagrams 7 and 8 also depend on the mentioned relationship. When the ratio $2 R / d$ increases, the curvature of stress line increases, and the curvature of the deformation line decreases. 


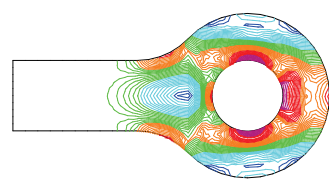

$\mathrm{U} 3-36^{\circ}$

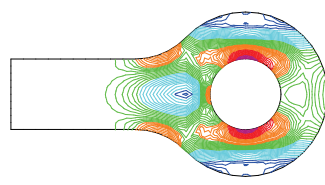

$\mathrm{U} 3-90^{\circ}$

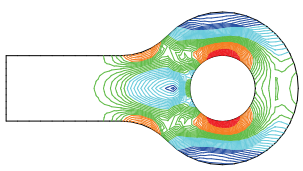

$\mathrm{U} 3-162^{\circ}$

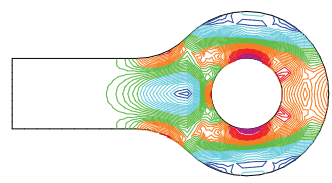

$\mathrm{U} 3-54^{\circ}$

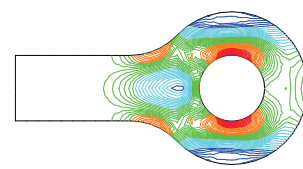

$\mathrm{U} 3-126^{\circ}$

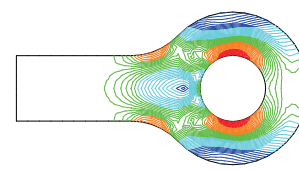

$\mathrm{U} 3-180^{\circ}$

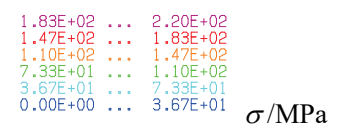

Figure 6 Representation of von Mises stress field $(\sigma)$ with associated scale for connecting lug U3

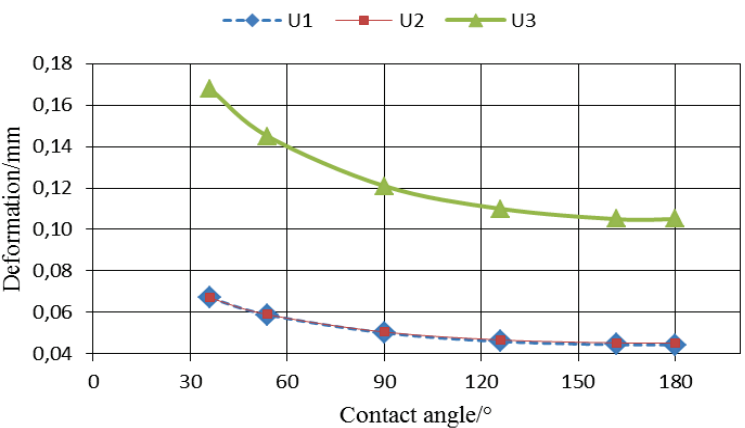

Figure 7 Diagram of maximum deformation dependence on contact angle between the axle and the connecting lug

$$
\multimap \mathrm{U} 1 \rightarrow-\mathrm{U} 2 \rightarrow-\mathrm{U} 3
$$

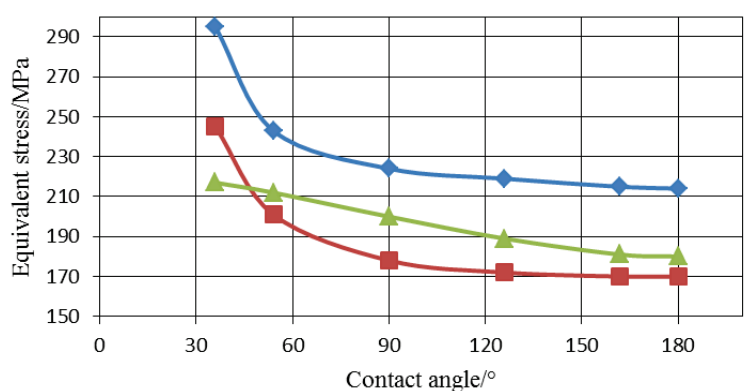

Figure 8 Diagram of maximum equivalent stress dependence on contact angle between the axle and the connecting lug

\section{EXPERIMENTAL WORK}

The aim of experimental investigation was to verify the numerical calculation of the model using physical (previously built) laboratory models. The experiment was performed at the Laboratory for stress and deformation measurements, Faculty of Mechanical Engineering, University of Belgrade. A new experimental method for contactless measurements, for three-dimensional optical strain and stress analysis based on Digital Image Correlation (Aramis-system) was used [11-15].

\subsection{Experiment Preparation}

To perform the measurements, a stochastic pattern must be applied onto the measuring points. The stochastic pattern is formed in such a way as to first apply white matte spray paint, and later black paint is lightly applied from a certain distance, so that black spots are formed (Fig. 9).

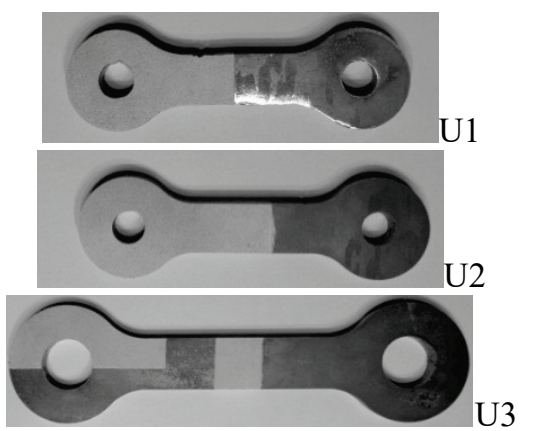

Figure 9 Stochastic pattern applied onto measuring points

\subsection{Experiment Setup}

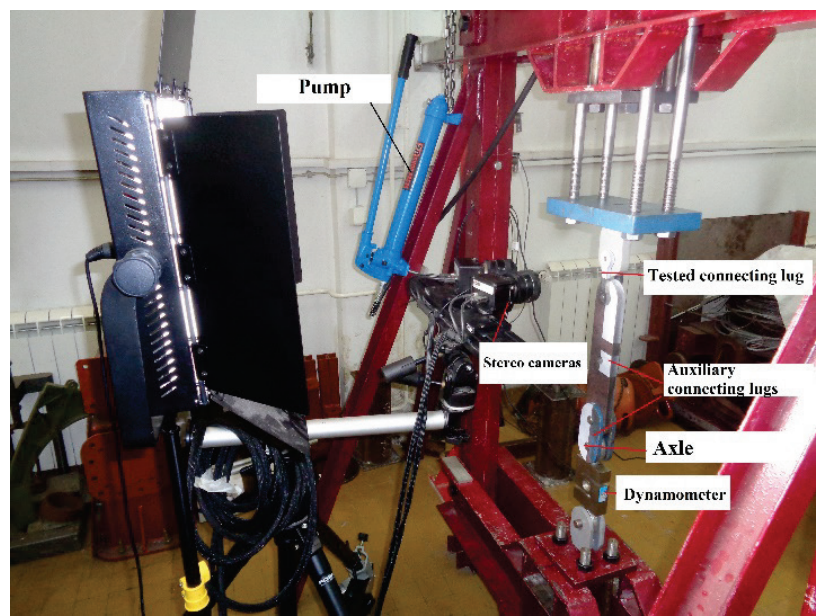

Figure 10 Experiment setup

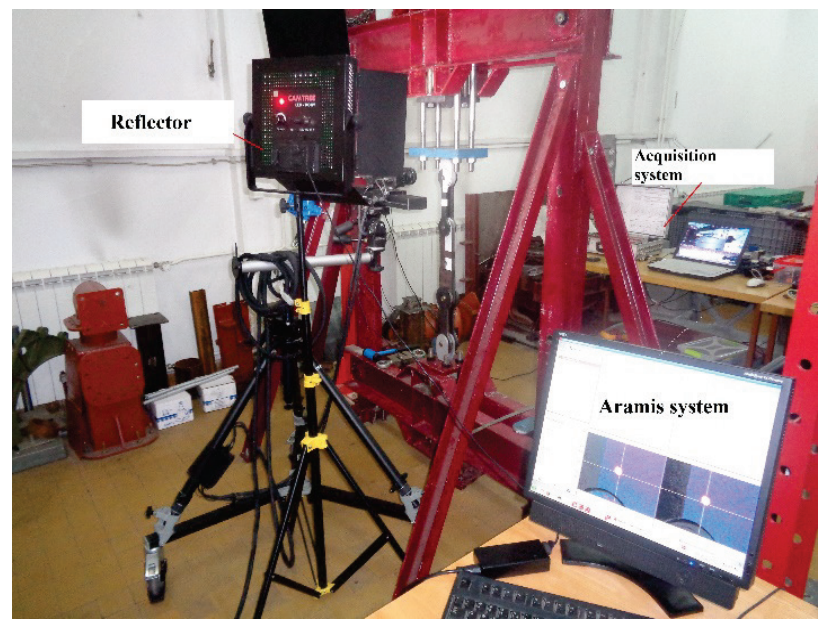

Figure 11 Arrangement of measuring equipment

Experiment setup is presented in Fig. 10. The vertical force is caused by the hydraulic cylinder leaning against the upper horizontal beam. The aim was to keep loading in a closed contour of the rigid frame, where two horizontal beams of the frame and vertical beams make up a closed contour. Arrangement of measuring equipment is presented in Fig. 11. 

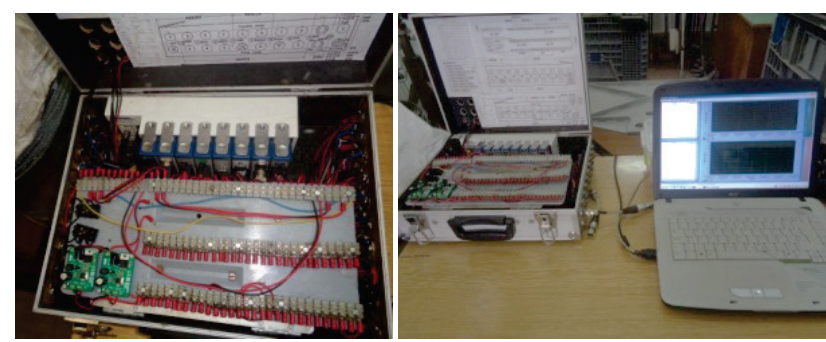

Figure 12 Appearance of data acquisition system

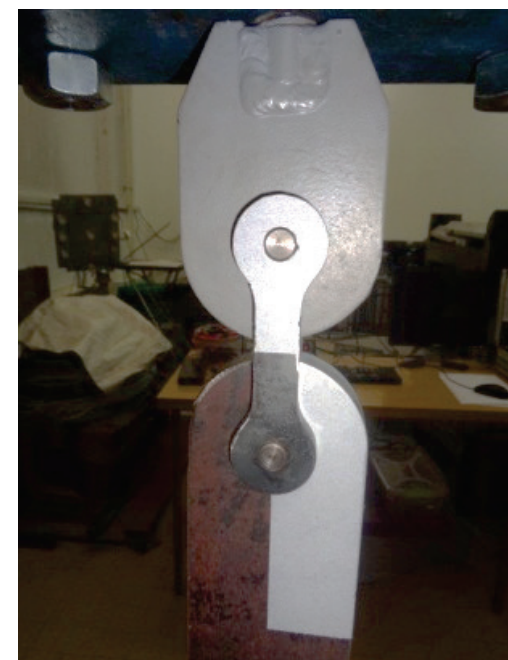

Figure 13 Connecting lug positioned for measurement
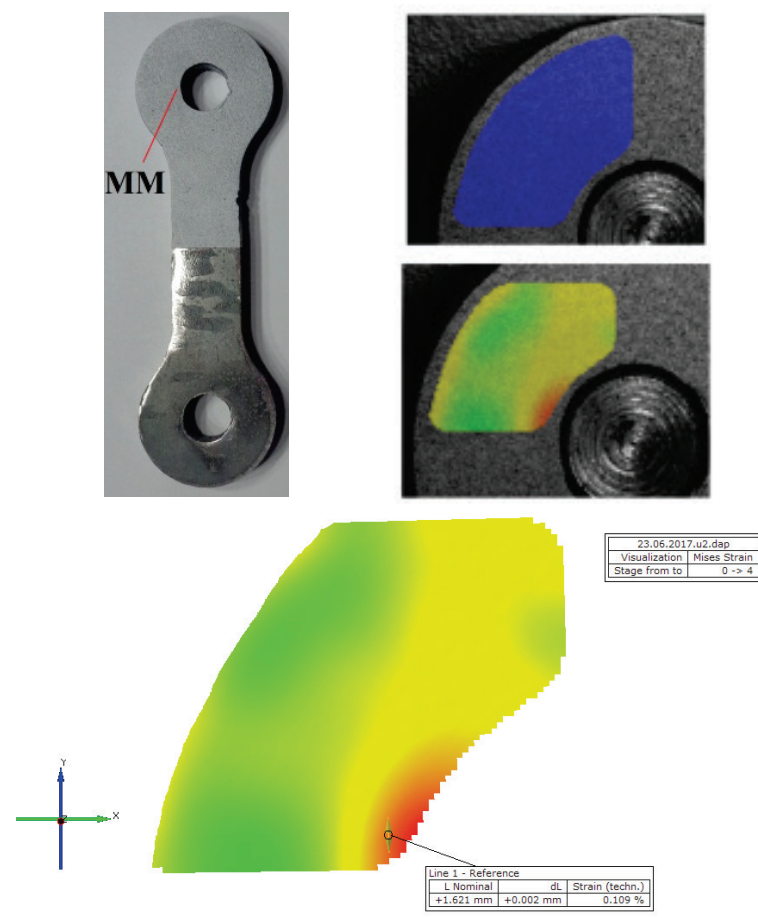

Figure 14 Representation of experimental results for connecting lug U1

\subsection{Measurement Procedure}

Each performed measurement implied gradual input of the force by using the hydraulic cylinder, at a $10 \mathrm{kN}$ pitch. Reading and control of force input was done using a dynamometer with measuring tapes, which was attached to a data acquisition device (Fig. 12). Fig. 13 shows a connecting lug positioned for measurement.

\subsection{Results of Experimental Investigation}

The figures below display the results of measurements obtained by the method for contactless measurements of stress and deformation of the firm GOM (Digital Image Correlation - Aramis system) [11].

Fig. 14 presents experimental model of the connected lug U1 with the stochastic pattern on the upper half and appropriate experimentally obtained results for cases without load and with maximum load.

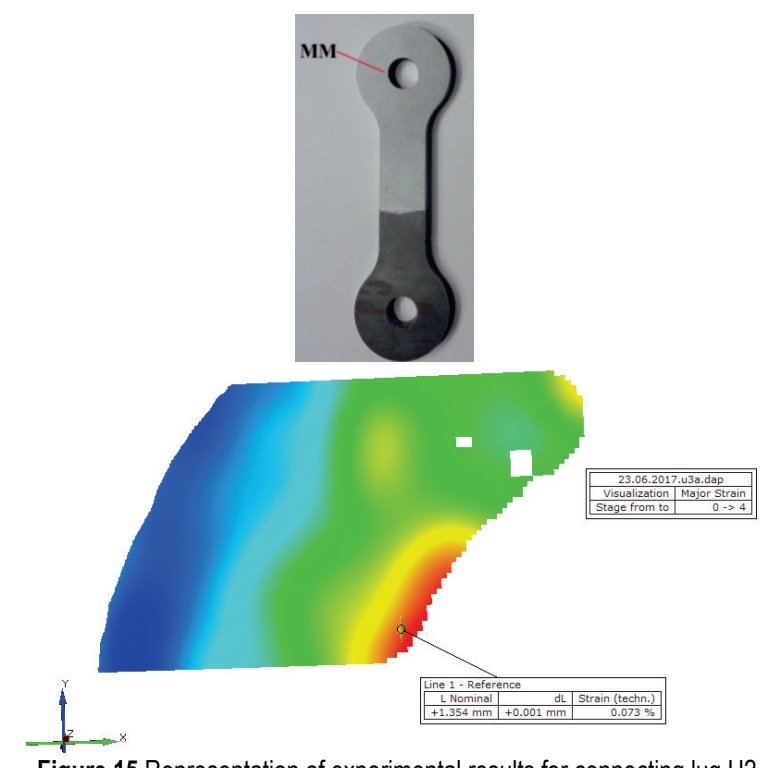

gure 15 Representation of experimental results for connecting lug U2

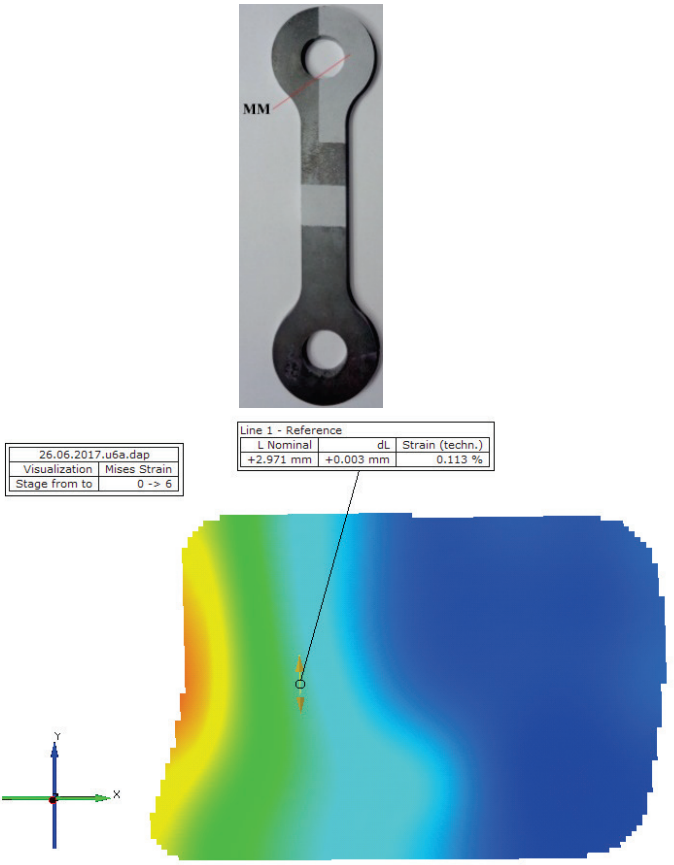

Figure 16 Representation of experimental results for connecting lug U3

In Figs. 14, 15 and 16 measurement areas are marked as MM. Obtained results for connecting lugs U2 and U3 are presented in Figs. 15 and 16.

\section{CONCLUSION}

Tab. 4 presents the results obtained by the finite element method in a "KOMPIS" software package and the 
experimental results. Appropriate von Mises stresses adopted for comparison correspond to places noticed in previous Figures. It can be concluded that stress distribution depends on clearance between the axle and the connecting lug, i.e., contact angle. In the connecting lug U1 the achieved contact angle was approx. $30^{\circ}$, in the connecting lug $\mathrm{U} 2$ approx. $170^{\circ}$ and in the connecting lug $\mathrm{U} 3$ approx. $60^{\circ}$. Based on the experiment, computational models from this work can be used in the future work in this field. It can be noticed that estimated stress values can vary within the range up to $20 \%$, due to the inability to accurately determine the contact angle in the experiment.

According to Figs. 4-6 it is concluded that the most satisfactory contact between the axle and the connecting lug is approx. $120^{\circ}$, due to the most favourable stress distribution is obtained and high stress concentration is avoided.

Table 4 Comparative analysis of obtained stresses

\begin{tabular}{|c|c|c|c|}
\hline $\begin{array}{l}\text { Designation of } \\
\text { con. lug }\end{array}$ & $\begin{array}{c}\text { Contact angle } \\
/^{\circ}\end{array}$ & $\begin{array}{c}\text { FEM Analysis } \\
\sigma / \mathrm{MPa}\end{array}$ & $\begin{array}{c}\text { Experiment } \\
\sigma / \mathrm{MPa}\end{array}$ \\
\hline \multirow{6}{*}{ U1 } & 36 & 248 & \multirow{6}{*}{259} \\
\hline & 54 & 236 & \\
\hline & 90 & 226 & \\
\hline & 126 & 213 & \\
\hline & 162 & 213 & \\
\hline & 180 & 213 & \\
\hline \multirow{6}{*}{$\mathrm{U} 2$} & 36 & 185 & \multirow{6}{*}{155} \\
\hline & 54 & 182 & \\
\hline & 90 & 175 & \\
\hline & 126 & 166 & \\
\hline & 162 & 158 & \\
\hline & 180 & 158 & \\
\hline \multirow{6}{*}{$\mathrm{U} 3$} & 36 & 218 & \multirow{6}{*}{212} \\
\hline & 54 & 214 & \\
\hline & 90 & 203 & \\
\hline & 126 & 188 & \\
\hline & 162 & 182 & \\
\hline & 180 & 180 & \\
\hline
\end{tabular}

\section{Acknowledgements}

This work was supported by the Ministry of Science and Technological Development of Serbia funded projects TR 35011, TR 35040 and ON174004.

\section{REFERENCES}

[1] Peterson, R. (1977). Koeficient i koncentratii naprajazenii. Izdateljstvo Mir, Moskva. (in Russian)

[2] Milovanović, A., Sedmak, A., Čolić, K., Tatić, U., \& Đorđević, B. (2017). Numerical Analysis of Stress Distribution in Total Hip Replacement Implant. Structural integrity and life, 17(2), 139-144.

[3] Pilkey, W. D., Pilkey, D. F., \& Peterson, R. E. (2008). Peterson s Concentration Factors, John Wiley and Sons, New York.

[4] Kozak, D., Damjanović, D., \& Katinić, M. (2016). Integrity Assessment of the Butt Weld Joint with Defect According to EN ISO 6520-1, Series 400A. Structural integrity and life, 16(2), 120-124.

[5] Ju, S. H. \& Rowlands, R. E. A. (1999). A three-dimensional frictional contact element whose stiffness matrix is symmetric. J. Appl. Mech., 66(2), 460-467. https://doi.org/10.1115/1.2791070

[6] Antoni, N. \& Gaisne, F. (2011). Analytical modelling for static stress analysis of pin-loaded with bush fitting. Applied Mathematical Modeling, 35, 1-21. https://doi.org/10.1016/j.apm.2010.05.002

[7] Shi, G., Shi, Y., Wang, Y., \& Bradford, M. A. (2008). Numerical simulation of steel pretensioned bolted endplate connections of different types and details. Engineering Structures, 30(10), 2677-2686. https://doi.org/10.1016/j.engstruct.2008.02.013

[8] Čelović, S., Tipsarević, M., Maneski, T., Vuherer, T., \& Kozak, D. (2015). Numerical-experimental analysis of the foldable containers strehgth. Tehnički vjesnik-Technical Gazzete, 22(6), 1527-1532. https://doi.org/10.17559/TV-20150112100813

[9] Bajić, D., Momčilović, N., Maneski, T., Balać, M., Kozak, D., \& Ćulafić, S. (2017). Numerical and experimental determination of stress concentration factor for a pipe branch model. Tehnički vjesnik-Technical Gazzete, 24(3), pp. 687692. https://doi.org/ 10.17559/TV-20151126222916

[10] Software KOMIPS, Faculty of Mechanical Engineering, Belgrade

[11] Software ARAMIS, GOM, Germany

[12] Sedmak, A., Milošević, M., Mitrović, N., Petrović, A., \& Maneski, T. (2012). Digital image correlation in experimental mechanical analysis. Structural integrity and life, 12(1), 39-42.

[13] Tatić, U., Čolić, K., Sedmak, A., Mišković, Ž., \& Petrović, A. (2018). Evaluation of the Locking Compression Plate Stress-Strain Fields. Tehnički vjesnik-Technical Gazette, 25(1), 112-117. https://doi.org/10.17559/TV-20170420121538

[14] Tatić, U., Miletić, V., Sedmak, S., Mitrović, N., Ezdenci, A., Gubeljak, L., Milošević, M. (2014). Influence of the Cavity Shape in Restorative Dentistry on the Stress-Strain Distribution in Dentine and Enamel Caused by Polymerization. Structural integrity and life, 14(3), 199-204.

[15] Čolić, K., Sedmak, A., Gubeljak, N., Burzić, M., Petronić, S. (2012). Experimental Analysis of Fracture Behaviour of Stainless Steel used for Biomedical Applications. Structural integrity and life, 12(1), 59-63.

\section{Contact information:}

Đorđe ĐURĐEVIĆ, Teaching Asist.

College of Applied Engineering Studies in Belgrade,

Nade Dimić 4, 11080 Zemun, Serbia

E-mail: djdjurdjevic@tehnikum.edu.rs

Nina ANĐELIĆ, Professor

University of Belgrade, Faculty of Mechanical Engineering,

Kraljice Marije 16, 11000 Belgrade, Serbia

E-mail: nandjelic@mas.bg.ac.rs

Taško MANESKI, Professor

University of Belgrade, Faculty of Mechanical Engineering

Kraljice Marije 16, 11000 Belgrade, Serbia

E-mail: tmaneski@mas.bg.ac.rs

Vesna MILOŠEVIĆ-MITIĆ, Professor

University of Belgrade, Faculty of Mechanical Engineering

Kraljice Marije 16, 11000 Belgrade, Serbia

E-mail: vmilosevic@mas.bg.ac.rs

Andrijana ĐURĐEVIĆ, Assist. Professor

College of Applied Engineering Studies in Belgrade,

Nade Dimić 4, 11080 Zemun, Serbia

E-mail: adjurdjevic@tehnikum.edu.rs

Pejo KONJATIĆ, Associate Professor

Mechanical Engineering Faculty in Slavonski Brod,

Trg Ivane Brlić Mažuranić 2, HR-35000 Slavonski Brod, Croatia

E-mail: pekon@sfsb.hr 